\title{
Status, knowledge, attitudes, and practices of 12-18-year old orphaned children pertaining to dental caries in an dental clinic by non-governmental organization at Phnom Penh, Cambodia
}

\author{
Yu Kubota ${ }^{1 *}$, Sutthi Jareonpituak ${ }^{2}$, Kulaya Narksawat ${ }^{2}$, Pratana Satitvipawee ${ }^{3}$ and Callum Durward ${ }^{4}$ \\ ${ }^{1}$ Preventive Dentistry Clinic, Niigata University Medical and Dental Hospital, Japan \\ ${ }^{2}$ Mahidol University, Department of Epidemiology, Thailand \\ ${ }^{3}$ Mahidol University, Department of Biostatistics, Thailand \\ ${ }^{4}$ University of Puthisastra, Faculty of Health Sciences, Cambodia
}

\begin{abstract}
This cross-sectional study examined the prevalence of dental caries and associated factors among children aged 12-18 years residing in orphanages at Phnom Penh, Cambodia. The study included 187 subjects (male $=103$, female $=84$, mean age $=13.28 \pm 1.51$ years), and the data was collected by means of oral examinations, DMFT scoring, oral health questionnaires based on the KAP model, and interviews conducted in a private dental clinic supported by a non-government organization. The overall caries prevalence was found to $85.2 \%$, and $30 \%$ of the children exhibited severe caries. The mean DMFT, DT, MT and FT scores were 3.58 $\pm 3.00,2.13$ $\pm 2.54,0.13 \pm 0.44$ and $1.32 \pm 1.68$, respectively.

The proportion of children with moderate knowledge about oral health, highly positive attitudes toward oral health, and moderate levels of oral hygiene practices were $63.6 \%, 69.6 \%$, and $67.3 \%$, respectively. Significant differences in factors related dental caries were observed among different age groups (p<0.01) and sweet intake groups ( $\mathrm{p}<0.05)$. Conversely, no significant associations were observed between dental caries status, and the levels of knowledge, attitudes, and practices pertaining to oral health.
\end{abstract}

The results of this study suggest that targeted oral health promotion programs are necessary to prevent dental caries in this population.

\section{Introduction}

Dental caries is the most common disease affecting $90 \%$ of the world's population [1]. Although the prevalence rates of childhood caries have markedly decreased in some developed countries because of community-level prevention programs and fluoridation programs $[2,3]$, they remain high in developing countries, such as Cambodia. In 2011, the Cambodia National Oral Health Survey reported that only $7 \%$ of children aged 6 years were caries free, and almost $80 \%$ of the children aged 12-13-years experienced dental caries. The mean $\mathrm{dmft}$ and DMFT scores (caries indicators) were 9.0, 3.5, and 4.2 among children aged 6-, 12, and 15- years, respectively [4].

Several orphaned children in Cambodia are either brought up by foreign parents or reside in orphanages. Oral health is often neglected among the latter group, and the children also have limited access to oral health service. It has been previously reported that children living in orphanages were likely to exhibit a higher prevalence of dental caries, gingivitis, and dental trauma [5], and a study conducted in India reported prevalence rates of $70.3 \%$ among children from various orphanages [6].

However, in Cambodia, there is little information available on the oral health status of orphaned children. Moreover, given that access to information on oral health is limited, it may be beneficial to conduct oral health education programs among orphaned children living in slums children in Cambodia. Therefore, the objectives of this study were to assess the prevalence of dental caries and associated factors among children 12-18-years residing in orphanages and visiting an NGO dental clinic at Phnom Penh, Cambodia.

\section{Materials and methods}

\section{Study site and population}

The Happy Dental Clinic, managed by the local NGO, One-2-One Cambodia, in Toul Kork District, Phnom Penh, Cambodia, was used as the site for collection of data from children residing in orphanages. Volunteer dentists in this clinic provide free dental services for poor children, mainly to those who are orphaned or live in slums.

Correspondence to: Yu Kubota, D.D.S., Ph.D., M.P.H., Preventive Dentistry Clinic Niigata University Medical and Dental Hospital, 2-5274 Gakkocho-dori, Chuo-Ku, Niigata City, 951-8514, Japan; Tel: +81-25-227-2858; Fax: +81-25227-0807; E-mail: yukubota@dent.niigata-u.ac.jp

Key words: dental caries, orphaned children, Cambodia

Received: April 04, 2017; Accepted: April 18, 2017; Published: April 21, 2017 
Kubota Y (2017) Status, knowledge, attitudes, and practices of 12-18-year old orphaned children pertaining to dental caries in an dental clinic by nongovernmental organization at Phnom Penh, Cambodia

\section{Sampling method}

This study included 187 children (male $=103$, female $=84$ mean age $=13.28 \pm 1.51$ years) from five orphanages cooperating with the NGO, One-2-One Cambodia. Children reporting oral health problems, particularly pain, were prioritized and visited the clinic first under the supervision of the orphanage staff.

\section{Dental caries status}

Oral health status, measured as the mean DT, MT, FT, and DMFT scores for each subject was recorded by means of an examination, as per the WHO Oral Health Surveys Basic Methods [7].

\section{Oral health knowledge, attitudes, and practices}

Factors associated with childhood dental caries among the orphaned children were recorded with help of a questionnaire-based interview using the knowledge-attitude-practice (KAP) model [8]. The questionnaire included 15 questions on the knowledge pertaining to oral health, and a score of " 1 " represented a correct response while "0" indicated an incorrect or uncertain response. The questionnaire also included 15 questions on the attitude toward oral health, and the four response options were strongly agree, agree, disagree, and strongly disagree scores "4", "3", "2" and "1", respectively. Finally, oral health practices were recorded with the help of 10 questions in three parts, (i.e., tooth brushing habits, dietary habits and dental visits), with three or four options and yes-no formatted questions.

\section{Level of knowledge, attitudes, and practices}

The levels were defined as follows [9]:

High: Over $80 \%$ of (maximum - minimum score) + minimum score

Moderate level: $60-80 \%$ of (maximum - minimum score) + minimum score

Low level: Below $60 \%$ of (maximum - minimum score) + minimum score

\section{Calibration of oral examination}

Intra-examiner calibration was performed to verify the validity and reliability of this study. One subject out of every five was examined twice on successive days, and Kappa statistics were used to compare the results. A kappa value of 0.87 indicated that the examinations were mostly in agreement and at the recommended level.

\section{Data entry and analysis}

The data was then recorded in an Excel spread sheet and exported to the Statistical Package for Social Science, version 18.0 for analysis. Descriptive statistics, including frequency, distribution, proportions, mean, median, maximum and minimum values, and standard deviation were used to present the data.

The Shapiro -Wilk Test was performed to verify normal distribution, and comparison of mean DMFT sores was performed using the MannWhitney and Kruskal -Wallis tests. The chi-square test was used to investigate associations between variables and dental caries, and a pvalue, less than 0.05 was considered statistically significance.

\section{Ethical consideration}

Ethical approval was obtained from the Ethics Review Committee for Human Research, Faculty of Public Health, Mahidol University (MUPH 2016-057).

\section{Results}

Overall, the mean DMFT, DT, MT, and FT scores were 3.58, $2.13,0.13$, and 1.32 , respectively. The mean DMFT scores were higher among females than those among males (Table 1).

The results showed that $30.0 \%$ of the children exhibited severe dental caries, $27.8 \%$ had moderate level dental caries, and $17.1 \%$ were caries free (Table 2).

Approximately $70 \%$ of the children brushed their teeth 3 times a day. However, the DMFT scores were found to be similar in all three groups. The DMFT scores of children who consumed fruits sweets. 3 times a week were likely to be higher than those of children who consumed less. Almost all the children had received dental treatments or oral prophylaxis before, and their DMFT scores were higher than those of the children who had received than no treatment.

Statistically significant differences in DMFT scores were observed between age groups $(p=0.008)$ and sweet intake groups $(p=0.015)$ (Table 3).

Nearly one -third of the children exhibited high levels of oral health knowledge, $30.0 \%$ reported moderate levels, and only $6.4 \%$ showed low levels. With regard to attitudes toward oral health, $69.6 \%$ of the children showed high levels, and $30.4 \%$ exhibited moderate levels. Notably, no one reported low levels. Moreover, $16.2 \%$ of the children showed high levels with regard to oral health practices, $67.3 \%$ exhibited moderate levels, and only $16.5 \%$ were regarded as low level in this section (Table 4 ).

No statistically significant differences in mean DMFT were observed between the levels of knowledge, attitudes, and practices pertaining to oral health (Table 4).

\section{Discussion}

\section{Mean DMFT, DT, MT and FT}

The mean DMFT and DT scores in this study were lower than those in the National Oral Health Survey conducted in Cambodia in $2011(\mathrm{DMFT}=3.76 \pm 3.59, \mathrm{DT}=3.63 \pm 3.52)$ [10]. However, the mean DMFT score was higher than that observed in the survey in Phnom Penh $(3.24 \pm 2.87)$. Moreover, the FT scores of this study were higher than those of the survey $(0.07 \pm 0.35)$. These results indicate that about $90 \%$ of the orphaned children included in this study had received dental services previously, whereas only $35 \%$ of the children (aged 12 13 years) from the general population included in the national survey had never received any dental treatment.

Table 1. Mean DMFT, DT, MT, and FT $(\mathrm{n}=187)$

\begin{tabular}{|c|c|c|c|c|}
\hline Variables & DMFT & DT & MT & FT \\
\hline & Mean (SD) & Mean (SD) & Mean (SD) & Mean (SD) \\
\hline Male & $3.50(2.97)$ & $2.0(2.24)$ & $0.12(0.37)$ & $1.38(1.71)$ \\
\hline Female & $3.68(3.47)$ & $2.3(2.86)$ & $0.14(0.51)$ & $1.24(1.66)$ \\
\hline Total & $3.58(3.00)$ & $2.13(2.54)$ & $0.13(0.44)$ & $1.32(1.68)$ \\
\hline
\end{tabular}

Table 2. Frequencies (number and percentage) of levels of dental caries $(n=187)$

\begin{tabular}{|c|c|c|}
\hline Severity level of dental caries & Number & Percentage \\
\hline Very severely affected (DMFT $\geq 6.6$ ) & 25 & 13.4 \\
\hline Severely affected (DMFT $4.5-6.5)$ & 31 & 16.6 \\
\hline Moderately affected (DMFT $2.7-4.4)$ & 52 & 27.8 \\
\hline Poorly affected (DMFT $1.2-2.6$ ) & 22 & 11.8 \\
\hline Very poorly affected (DMFT $<1.2$ ) & 25 & 13.4 \\
\hline Not affected (DMFT $=0$ ) & 32 & 17.1 \\
\hline
\end{tabular}

Mean $\pm \mathrm{SD}=3.58 \pm 3.00 \quad$ Median $=3.00 \quad$ Min $-\mathrm{Max}=0-20$ 
Kubota Y (2017) Status, knowledge, attitudes, and practices of 12-18-year old orphaned children pertaining to dental caries in an dental clinic by nongovernmental organization at Phnom Penh, Cambodia

Table 3. Association between mean DMFT and factors associated with dental caries $(\mathrm{n}=$ 187)

\begin{tabular}{|c|c|c|c|c|}
\hline \multirow{2}{*}{ Variables } & \multirow{2}{*}{ Number (\%) } & \multicolumn{2}{|c|}{ DMFT } & \multirow{2}{*}{ p-value } \\
\hline & & Mean & SD & \\
\hline \multicolumn{5}{|l|}{ Sex } \\
\hline Male & $103(30.0)$ & 3.50 & 2.97 & $0.88^{\mathrm{a}}$ \\
\hline Female & $84(63.6)$ & 3.68 & 3.47 & \\
\hline \multicolumn{5}{|l|}{ Age group } \\
\hline 12- 13 years old & $129(68.9)$ & 2.99 & 2.45 & $0.008^{\mathrm{a}}$ \\
\hline 14- 18 years old & $58(31.1)$ & 4.88 & 4.18 & \\
\hline \multicolumn{5}{|l|}{$\begin{array}{l}\text { Frequency of } \\
\text { tooth brushing }\end{array}$} \\
\hline$>3$ times a day & 127 (67.9) & 3.57 & 3.23 & $0.84^{\mathrm{b}}$ \\
\hline Twice a day & $52(27.8)$ & 3.60 & 3.30 & \\
\hline Once a day & $8(4.3)$ & 3.63 & 2.26 & \\
\hline \multicolumn{5}{|l|}{ Fruit intake } \\
\hline$>3$ times a week & $54(28.8)$ & 3.72 & 2.92 & $0.26^{\mathrm{b}}$ \\
\hline 1-3 times a week & $119(63.6)$ & 3.65 & 3.35 & \\
\hline Never & $14(7.6)$ & 2.43 & 2.87 & \\
\hline \multicolumn{5}{|l|}{ Sweet intake } \\
\hline$>3$ times a week & $76(40.6)$ & 4.41 & 3.79 & $0.015^{\mathrm{b}}$ \\
\hline 1-3 times a week & $98(52.4)$ & 3.16 & 2.67 & \\
\hline Never & $13(7.0)$ & 1.85 & 1.57 & \\
\hline \multicolumn{5}{|l|}{$\begin{array}{l}\text { Visited dentists } \\
\text { bore }\end{array}$} \\
\hline Yes & $182(97.3)$ & 3.62 & 3.50 & $0.16^{\mathrm{a}}$ \\
\hline No & $6(2.7)$ & 2.33 & 3.19 & \\
\hline
\end{tabular}

${ }^{\mathrm{a}}$ Mann - Whitney test, ${ }^{\mathrm{b}}$ Kruskal -Wallis test

Table 4. Association between mean DMFT and level of knowledge, attitude, and practices pertaining to oral health $(\mathrm{n}=187)$

\begin{tabular}{|c|c|c|c|c|}
\hline \multirow{2}{*}{ Level (Score) } & Number & \multicolumn{2}{|c|}{ DMFT } & \multirow{2}{*}{ p-value } \\
& $(\mathbf{\%})$ & Mean & SD & \\
\hline Knowledge level & & & & \\
\hline High (12 -15) & $56(30.0)$ & 3.89 & 3.33 & $0.72^{\mathrm{b}}$ \\
\hline Moderate (9-11) & $119(63.6)$ & 3.44 & 3.18 & \\
\hline Low (0 -8) & $12(6.4)$ & 3.50 & 2.97 & \\
\hline Attitude level & & & & \\
\hline High (34 -40) & $116(69.6)$ & 3.54 & 3.00 & $0.58^{\mathrm{a}}$ \\
\hline Moderate (10 -33) & $71(30.4)$ & 3.70 & 3.55 & \\
\hline Practice level & & & & \\
\hline High (20-23) & $28(16.2)$ & 3.04 & 3.20 & $0.76^{\mathrm{b}}$ \\
\hline Moderate (16-19) & $126(67.3)$ & 3.58 & 2.90 & \\
\hline Low (5-15) & $31(16.5)$ & 4.23 & 4.55 & \\
\hline
\end{tabular}

${ }^{a}$ Mann -Whitney test, ${ }^{b}$ Kruskal -Wallis test

The mean DMFT scores observed in this study were higher than those observed in previous studies, such as those conducted in India and Yemen where the mean DMFT scores among orphaned children aged 12-15 years were $3.56 \pm 2.06$, and $2.06 \pm 1.94$, respectively. Moreover, the DT and FT scores were also lower among orphaned children $[11,12]$, suggesting that they exhibited untreated caries more frequently and did not use dental services regularly, despite having received dental treatment or prophylaxis previously. To improve the dental caries status, the children must be encouraged to visit a dental clinic regularly.

\section{Caries prevalence}

In this study, $82.9 \%$ of the children exhibited caries, and this was similar to the rates observed in the National Oral Health Survey, 2011(12 - 13 years: $80.4 \%, 15$-17-years: $84.5 \%$ ) [4]. Moreover, this value was higher than that observed in the rural districts of Cambodia (52\%)
[10]. The studies in India and Yemen reported that $88.5 \%$ and $84.7 \%$ of orphaned children had suffered from caries, respectively [11, 12]. Compared with other countries' studies in Southeast Asia, it was also likely to be higher [13-16].

In this study, $30.0 \%$ of the children exhibited severe dental caries. WHO aim to reduce the mean DMFT score to less than three among children aged12-years [17]. However, more than half of the children included in this study exhibited DMFT score of 3, thus highlighting the need for oral health promotion programs focusing on the severely affected group.

\section{Association between mean DMFT and, the level of knowledge, attitudes, and practices pertaining to oral health}

\section{Knowledge about oral health}

Majority of the children exhibited high levels of knowledge regarding the cause of dental caries, the relationship between oral and general health, and the importance of tooth brushing. On the other hand, a lower percentage of them gave correct answers to the questions regarding treatments for dental caries and tooth brushing. Majority of the children believed that extraction was the best treatment for decayed teeth, dental caries could only be cured with special medicines, and brushing teeth before meals was more effective in preventing dental caries than doing it after meals.

A previous study examining oral health knowledge reported that $15.0 \%$ of 12-13-year-old school children in the Yangon Region of Myanmar had low levels of knowledge about oral health [18]. The children included in this study exhibited better knowledge of oral health, and most of them had attended dental services, including oral health education, in the Happy Dental Clinic previously. This suggested that the oral health education provided improved their knowledge of oral health.

\section{Attitudes toward oral health}

With regard to attitudes towards oral health, most of the children exhibited high levels attitudes (mean score: 36.52, median score: 40 ), and these results were similar to those of the study conducted in Myanmar [18]. All the children agreed with the statement that even in the absence of tooth pain, regular dental check-ups were necessary. Approximately $95 \%$ of the children included in this study had experienced attending dental services and therefore, understood the importance of regular check-ups. This suggests that ensuring that the children attended dental services helped them maintain positive attitudes toward oral health.

\section{Oral health practices}

Approximately $69.7 \%$ of the children included in this study brushed their teeth $>3$ times a day while $98.7 \%$ used tooth pastes. The National Oral Health Survey conducted in Cambodia in 2011, reported that $19.2 \%$ of children aged 12-17-years children brushed their teeth $>3$ times a day, and $96.8 \%$ used tooth paste [10]. These results suggest that children residing at orphanages exhibited better tooth brushing habits of tooth brushing than children from general population.

With regard to sweet consumption, the children were likely to consume sugary beverages more frequently than sweets, biscuits, and cakes, and these findings were in line with those reported by the National Oral Health Survey. The study in India also reported similar results with $85 \%$ of 5-16-year-old orphaned children consuming sugary soft drinks more than once a week $[10,19]$. Children who consumed sweets 
frequently were more likely to suffer from dental caries, suggesting that controlling dietary habits helped in the prevention of dental caries.

Almost all the children had received dental treatments or prophylaxis previously. The children residing at the orphanages could access take dental services free of charge and were encouraged to visit the dentist regularly in this study. Hence, they had better accessibility to dental services than children from the general population. Children who had visited the dentist before exhibited higher DMFT scores than those who had not, with DT, MT, and FT scores in the former group being, $2.13 \pm 3.50,0.13 \pm 0.45$ and $1.36 \pm 1.69$, respectively. The corresponding numbers in the latter group were $2.33 \pm 2.51,0$, and 0 , respectively, suggesting that the difference between the groups lay in the number of treated teeth.

This study had several limitations. First, the cross-sectional study design did not allow us to determine the true temporal sequence of exposure and outcomes, thus preventing an inference of causality. Second, the subjects were prioritized based on their oral health problems, especially pain, under the supervision of the orphanage staff, and this may have resulted in selection bias. Last, the small number of subjects, $(\mathrm{n}=187)$, made it difficult to examine associations between dental caries status and other associated factors.

In conclusion, first, the dental caries status of orphaned children aged 12-18-years and attending an NGO dental clinic at Phnom Penh, Cambodia was similar to that of children from the general Cambodian population. The results of this study show that oral health promotion programs should be targeted toward groups moderately and severely affected by caries. Moreover, orphanage staff should be provided with oral health education to improve their knowledge and practice levels.

\section{Acknowledgements}

This study was supported by the Faculty of Public Health, Mahidol University. The authors would also like to express their appreciation for the One-2-One staff for their help with conducting this study in Cambodia.

\section{References}

1. Williams DM (2011) Global oral health inequalities: the research agenda. Adv Dent Res 23: 198-200. [Crossref]

2. Survey of Dental Diseases (2011) Ministry of Health Labor and Welfare. http://www. mhlw.go.jp/toukei/list/d1/62-23-02.pdf
3. National Oral Health Survey (2000-2012) Ministry of Health Labor and Welfare, Korea

4. Chher T, Turton B, Hak S, Beltran E, Courtel F, et al. (2016) Dental caries experience in Cambodia: Findings from the 2011 Cambodia National Oral Health Survey. $J$ Int Oral Health 8: 1-7.

5. O'Sullivan EA, Stephens AJ (1997) The oral and dental status of children residing in a Romanian orphanage. Int J Paediatr Dent 7: 41-42. [Crossref]

6. Dixit S1, Chaudhary M, Singh A (2009) Molluscum contagiosum and dental caries: a pertinent combination. J Indian Soc Pedod Prev Dent 27: 197-201. [Crossref]

7. Oral Health Surveys Basic Methods, Fifth Edition (2013) WHO

8. Watt RG (2005) Strategies and approaches in oral disease prevention and health promotion. Bull World Health Organ 83: 711-718. [Crossref]

9. Bloom BS (1971) Handbook on formative and summative evaluation of student learning. New York.

10. Cambodia National Oral Health Survey 2011

11. Shanbhog R, Godhi BS, Nandlal B, Kumar SS, Raju V, et al. (2013) Clinical consequences of untreated dental caries evaluated using PUFA index in orphanage children from India. $J$ Int Oral Health 5: 1-9. [Crossref]

12. Al-Maweri SA, Al-Soneidar WA, Halboub ES (2014) Oral lesions and dental status among institutionalized orphans in Yemen: A matched case-control study. Compemp Clin Dent 5: 81-84.

13. Bereau of Dental Health, Department of health, Ministry of Public Health (2013) National Oral Health Survey, Thailand 2012. 1st ed., Office of The War Veteran Organization of Thailsnd Printing. Bangkok.

14. Van Palenstein Helderman WH, Truin GJ, Can N, Khanh ND (2001) The possibility of previous epidemiological data to serve as baseline for future national oral health surveys--a study in Vietnam. Int Dent J 51: 45-48. [Crossref]

15. Oral Health Devision, Ministry of Health, Malaysia 2010

16. Gao XL, Hsu CY, Loh T, Koh D, Hwamg HB, et al. (2009) Dental caries prevalence and distribution among preschoolers in Singapore. Community Dent Health 26: 12-17. [Crossref]

17. Poul Erik-Peterson (2003) The World Oral Health Report 2003: continuous improvement of oral health in the 21 th century - the approach of the WHO Global Oral Health Program. Community Dent Oral Epidemiol 31 Suppl 1: 3-23. [Crossref]

18. Phyo AZ, Chansatitporn N, Narksawat K (2013) Oral Health Status and Oral Hygiene Habits among Children Aged 12-13 Years in Yangon, Myanmar. Southeast Asian J Trop Med Public Health 44: 1008-1014. [Crossref]

19. Hans R, Thomas S, Dagli R, Bhateja GA, Sharma A, et al. (2014) Oral health knowledge, attitude and practices of children and adolescents of orphanages in jodhpur city rajasthan, India. J Clin Diagn Res 8: ZC22-25. [Crossref]

Copyright: $(2017$ Kubota Y. This is an open-access article distributed under the terms of the Creative Commons Attribution License, which permits unrestricted use, distribution, and reproduction in any medium, provided the original author and source are credited. 